\title{
Studying the factors that affects the efficiency of water turbines
}

\author{
Ahmed Reda Abdelfatah Abdelrahman \\ Dakahlia STEM High School \\ Kafr Sad, Damietta, Egypt \\ Ahmed.1319031@stemdakahlia.moe.edu.eg \\ Hossam Mohamed Abdelfattah Saber \\ Dakahlia STEM High School \\ Kafr Sad, Damietta, Egypt \\ Hossam.1319057@stemdakahlia.moe.edu.eg \\ DOI: $10.31364 / \mathrm{SCIRJ} / \mathrm{v} 9 . \mathrm{i05}$.2021.P0521856 \\ http://dx.doi.org/10.31364/SCIRJ/v9.i05.2021.P0521856
}

\begin{abstract}
Our beloved country, Egypt, is drowning in the swamps of problems which are called Egyptian grand challenges that prevent it from entering the race among the developed countries. These grand challenges range from improving uses of alternative energy, arid areas, over population, etc. improving uses of alternative energy is the scoop of this research. There are many types of alternative energy but, this research focus on hydroelectricity especially, water turbines. Water turbines are generating electricity by converting mechanical energy into electricity. In this research, the purpose is studying the factors that effect on the efficiency of water turbines by using the relation between cross-section area and velocity. And also, by using the relation between velocity and power which is cubic relationship and surely the relation between pressure and height. By looking on prior researches trying to know more about hydroelectricity and solving many problems such as water demand and low dissolved oxygen levels in the water. These problems can be solved by using the same idea of the dams but, use sea water which storage in a big tank. And knew about $\mathrm{V}$-shape of the dams or water turbines. Scientific laws and methods have been used trying to increase the efficiency of water turbines. Concluding that increasing the cross-section area in front of blades to increase the pressure on them. And decreasing the cross-section area that distal to the area that in front of the turbine to increase the velocity and increasing electricity power output. The purpose of this research has been achieved and many problems have been solved from prior researches.
\end{abstract}

Index Terms - Alternative energy, Blades, Hydroelectricity, Water turbines. (key words)

\section{INTRODUCTION}

It is a great shame to say that our beloved country Egypt suffers from many great problems. Currently, we are dealing with the issue of alternative energies and improving uses of it. Alternative Energy refers to energy sources other than fossil fuels. This includes all renewable sources. Alternative energy sources are looked upon favorably because they do not directly emit greenhouse gases in their production but of course all forms of energy have their own costs, benefits and tradeoffs. There are many types of alternative energies such as Tidal energy, Biomass energy, Wind energy, geothermal energy, Biofuels, wave energy, nuclear energy, solar power and Hydroelectric energy, shown in figure (1). Hydroelectric energy carries with it a number of benefits. Not only is it a clean source of energy, which means it doesn't create pollution and the myriad issues that arise from it, but it is also a renewable energy source. Hydroelectric energy is a form of energy that harnesses the power of water in motion such as water flowing over a waterfall to generate electricity, figure (2) shown the uses of energy in Egypt. Egypt consumes a lot of unrenewable energies Which are $50.7 \%$ oil, $44.7 \%$ natural gas, $0.5 \%$ coal, $0.6 \%$ of renewable energies and $3.5 \%$ hydroelectric energy.

Hydropower is Egypt's third-largest energy source after fossil
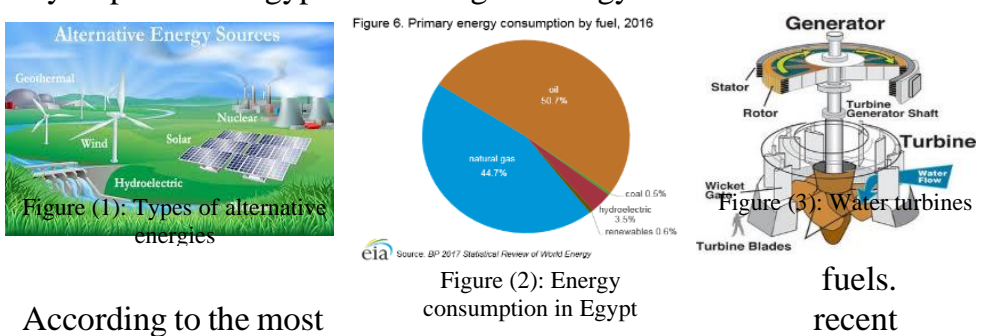

According to the most consumption in Egypt

recent $2.8 \mathrm{GW}$ and generated 13.8 terawatt hours of hydroelectricity in 2016, accounting about 7.2\% of Egypt's total power generation, as shown in Table (1). It shown projects that have been applied in Egypt about hydroelectric energy. Most of the country's hydroelectricity comes from the Aswan High Dam and the Aswan Reservoir Dams across the Nile River. Hydroelectric energy is generated by Water turbines, that shown in figure (3). Water turbines (hydro turbines) are placed in the base of dams and rivers, as shown in figure (4). They generate electricity by their rotary blades the rotate by moving water. I made observation about this solution to the problem of improve uses of alternative energy and I found that it's the best solution for its advantage like it is clean fuel source, domestic source of energy, relies on the water cycle. But Hydropower plants can cause low dissolved oxygen levels in the water, a problem that is harmful to riparian. So, the scoop of this research is Hydroelectricity, especially water turbines. The purpose is studying the factors that effect on the efficiency by applying scientific laws and methods by using STEM subjects like Physics (PH.1.09), the 
relation between cross-section area and velocity. In Geology (ES.1.10), knowing about the mineral ore of lead. In math (MA.1.08), using exponential function to represent the relation between the hydraulic gradient and velocity. In chemistry (CH.1.09), knowing about composites. In social studies (SS.1.05), solving the problem of water demand and low dissolved oxygen levels in the water. From prior researches, there is some problem and ideas that face hydroelectric dams like water demand and low dissolve oxygen in the water that will be solved in this research. And many ideas have taken like Vshape of water turbines.

\section{MATERIALS}

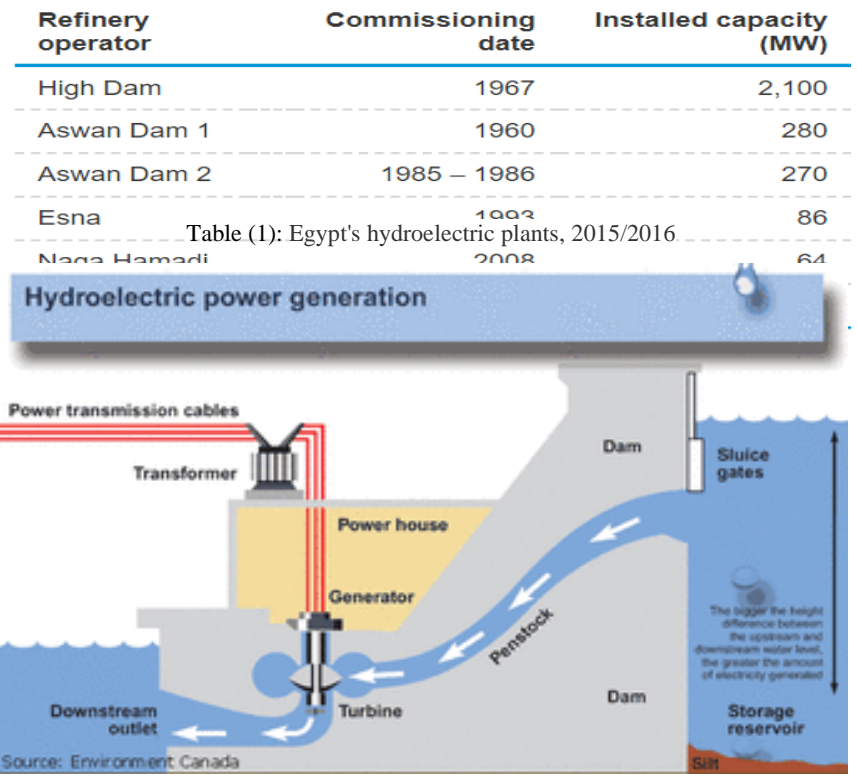

1. Campsites: compounds are manufactured by means of a process in which the fibers are embedded in another material. Usually, this will result in a stronger material

Figure (4): The mechanism of water turbines

and provide better qualities than both materials. Compounds not only help make stronger and lighter materials but also help extend the life of the materials, as shown in Figure (5).

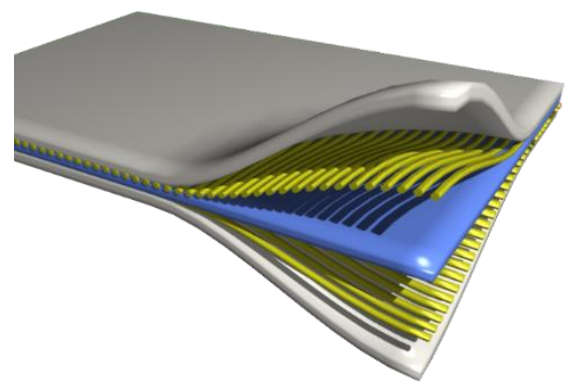

Figure (5): 3D composites

\section{LITERATURE REVIEW:}

(United States Patent No. US4843249A, 1988) made a research paper that said that "A system for generating electric energy from sea waves uses a large number of turbine units, preferably disposed of in a generally $\mathrm{V}$-shaped array. By properly positioning them in relation to the water surface and the direction of the forward wave advance, in some cases by providing means to convert the path to Water flow, causes the turbine wheels to spin to drive the linked generators and thus to produce electrical energy. The control subsystem automatically adjusts the vertical position of the turbine wheels to accommodate tidal variations". (United States Patent No. US4843249A, 1988).

- (United States Patent No. US4843249A, 1988) the research has mostly focused on the fields of generating electric energy from sea waves uses a large number of turbine units. In my opinion the points of strengths are:

1. They use water turbines and put them in the seas

2. They discovered that V-shaped array is a good idea for the turbines.

And the point of weakness is: they didn't discuss the factor that effect of generating electricity by turbines in the seas.

(Fearnside et, 1997) made a research paper that said that "Hydroelectric dams in tropical forest areas emit carbon dioxide and methane. So how to calculate these emissions and their impacts, and how to make comparisons with global warming contributions to alternative energy sources such as fossil fuels. An example of the Tucuruí Dam in Brazil was examined to illustrate these differences. This paper extends a previous analysis to 100 years and explores the differences between these emissions and similar fossil fuel emissions. Factors considered here in the calculation of emissions for the Tucuruí Dam include primary stock, carbon distribution and degradation rates. Factors that have not been considered include nitrous oxide sources, methane emissions, water passing through the turbines, and emissions from deforestation. The timing of emissions varies between hydroelectric and thermal power generation, as hydro produces a large pulse of carbon dioxide emissions in the first years after filling the tank while heat produces a steady flow of gases in proportion to the energy generated. According to the calculations presented in this paper, the average carbon dioxide molecule in the atmospheric load contributed by Tucuruí was present in the atmosphere 15 years ago. This means that given the 100-year time horizon, a ton of CO2 emitted from Tucuruí has a global warming effect of $15 \%$ more than a ton emitted from fossil fuels and with that hydroelectric energy is still 3-4 times better than fossil fuel generation. If the discount rate reaches $15 \%$, the situation is reversed, and fossil fuel generation becomes more attractive from a global warming perspective". (Fearnside et, 1997).

- (Fearnside et, 1997) the research has mostly focused on the fields of emissions by hydroelectric dams. In my opinion the points of strengths are:

1. Discussing the deference between hydroelectric dam's emissions and similar fossil fuel emissions.

2. A ton of $\mathrm{CO} 2$ emitted from Tucuruí has a global warming effect of $15 \%$ more than a ton emitted from fossil fuels and with that hydroelectric energy is still 34 times better than fossil fuel generation. 
1. There are factors that haven't been considered include nitrous oxide sources, methane emissions, water passing through the turbines, and emissions from deforestation.

2. If the discount rate reaches $15 \%$, the situation is reversed, and fossil fuel generation becomes more attractive from a global warming perspective.

(Yamba et, 2011) made a research paper that said that "The study analyzed the effects of various factors on the potential of hydroelectric power to include climate variability and water demand. An assessment of the historical energy potential (19702000) with respect to climate variability has been made in current hydroelectric power schemes (Kahura Bassa, Kariba, Cafu George and Itzi Tizi) in the Zambezi River Basin. The relationship of hydropower with climate variability was searched with the aim of monitoring the extent of impact and in order to predict future forecasts of hydropower potential, general trading models (GCM) were used. The simulated monthly precipitation was extracted from GCM for each sub-basin and was used to calculate future precipitation. Future demand for water in the Zambezi River is estimated based on the population growth rate in each sub-basin. The water balance model, with rainfall and water demand inputs, was used to determine the expected surface runoff of the Zambezi sub basins. Based on the expected surface runoff operations of the sub-basins, the storage capacities of the tanks were estimated. The results revealed a strong relationship between hydropower potential and climate variability. The study also revealed that climate, projected dry years, floods and increased water demand. The results indicate that the potential of hydropower is tilted towards a gradual limit”. (Yamba et, 2011).

- (Yamba et, 2011) the research has mostly focused on the fields of effects of various factors on the potential of hydroelectric power. In my opinion the points of strengths are:

1. They discuss the relationship of hydropower with climate variability.

2. General trading models (GCM) were used.

And the point of weakness is: The results indicate that the potential of hydropower is tilted towards a gradual limit. And that because of eater demand and climate change. But they didn't discuss solution as use seas to solve the problem of water demand.

(Atabani et, 2012) made a research paper that said that "Since fossil fuels are depleted day by day, alternative fuel is needed to meet energy demand. Biodiesel is one of the best available resources recently emerging. In this paper, a detailed review has been made to highlight the various aspects related to biodiesel. These include biodiesel raw materials, extraction and production methods, properties and characteristics of biodiesel, potential problems and solutions for the use of vegetable oils, the advantages and disadvantages of biodiesel, economic feasibility, and finally the future of biodiesel. High-ranking journals were the preferred option. Like scientific research and articles or some internal reports from reputable organizations such as the International Energy Agency (IEA) and Energy Information Administration (EIA) and BP as cited (BP). It is clear that the search for beneficial biodiesel sources should focus on feedstocks that provide greenhouse gas reductions. These feedstocks include inedible oils such as Jatropha curcas and Calophyllum inophyllum, and recently microalgae and GM plants have emerged as feedstocks for biodiesel production. It was also found that continuity in the esterification process is another option to reduce the cost of production. Currently, biodiesel can be more effective if used as a supplement to other energy sources". (Atabani et, 2012).

- (Atabani et, 2012) the research has mostly focused on the fields of biodiesel. In my opinion the points of strengths:

1. The discuss biodiesel raw materials, extraction and production methods, properties and characteristics of biodiesel, potential problems and solutions for the use of vegetable oils, the advantages and disadvantages of biodiesel, economic feasibility, and finally the future of biodiesel.

2. They focused on search for beneficial biodiesel sources that provide greenhouse gas reductions.

And the points of weaknesses are:

1. They didn't search for more solution to decrease the cost of production.

2. Biodiesel is still little harmful to the environment but, not more than petroleum diesel.

(Mao et, 2015) made a research paper that said that "Alternative energy plays a critical role in sustainable energy development. The literature on alternative energy has attracted increasing attention as the research outputs expand. Based on the expansion of the Science Quotation Index (SCI-E) and the Social Science Citation Index (SSCI), a bibliometric analysis of research outputs on alternative energy and future directions has been performed. Research has mostly focused on the fields of energy, fuel and environmental science. It was bioenergy and solar energy. Among the countries, the United States has been a pioneer in research on alternative energy. The United States of America has played a major role in academic cooperation with China, the United Kingdom, Canada, Germany, Italy, South Korea and Spain. The National Renewable Energy Laboratory (USA) contributed more to alternative energy, and more specialized, the College of Electrical and Computer Engineering $(\mathrm{TP}=36)$ was the most productive at the National University of Technology in Athens. It was interesting to note that solar or wind energy was taken care of for the first five or ten years, and then switched to bioenergy. Bioenergy received the most attention in 7 types of alternative energy. Forests, energy crops, and switch herb were the main bioenergy sources and fermentation was the commonly used transformation technology. Production of biogas, biodiesel and bioethanol was more common in bioenergy studies. Air and solar energy research have focused mainly on energy use approaches. Switching devices such as wind turbines and solar cells have received the most attention to improve production efficiency". (Mao et, 2015).

- (Mao et, 2015) the research has mostly focused on the fields of energy, fuel and environmental science. They were interested in bioenergy. In my opinion the points of strengths are:

1. They focused on bioenergy as source of energy. 
2. They focused on fermentation as commonly used transformation technology.

3. They take care also about solar cells and wind turbines as source of energy.

4. Biodiesel is less polluting than petroleum diesel

And the point of weakness is that:

1. The source of bioenergy is forests that may be harmful to the environment.

2. Biogas and bioethanol may cause increase global warming.

\section{ANALYSIS:}

In this research paper scientific laws and methods have been applied, like Continuity equation and Bernoulli equation and faraday's law, to increase the efficiency of water turbine that is related to fluids flow, especially water flow.

- Continuity equation: It states that: the fluid "mass flow rate" must be the same at any cross section of the pipe. $\mathrm{AV}=$ Constant $\quad$ (A: area) (V: velocity)

The relationship between area and velocity is inverse relationship, as shown in figure (6). Increasing the efficiency of water turbines by decrease the cross-section area to increase the velocity, in figure (7) as shown in region (1). And in front of the turbine by increasing the cross-section area to decrease the velocity and increase pressure, as show in region (2).

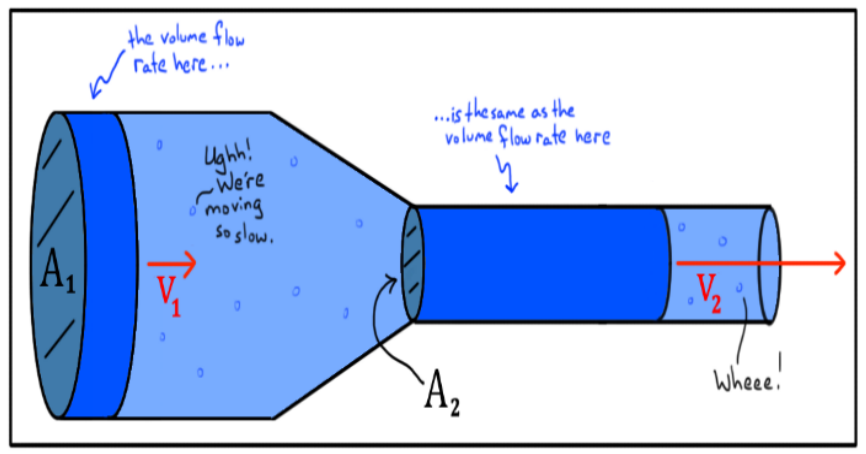

Figure (6): Mass flow rate

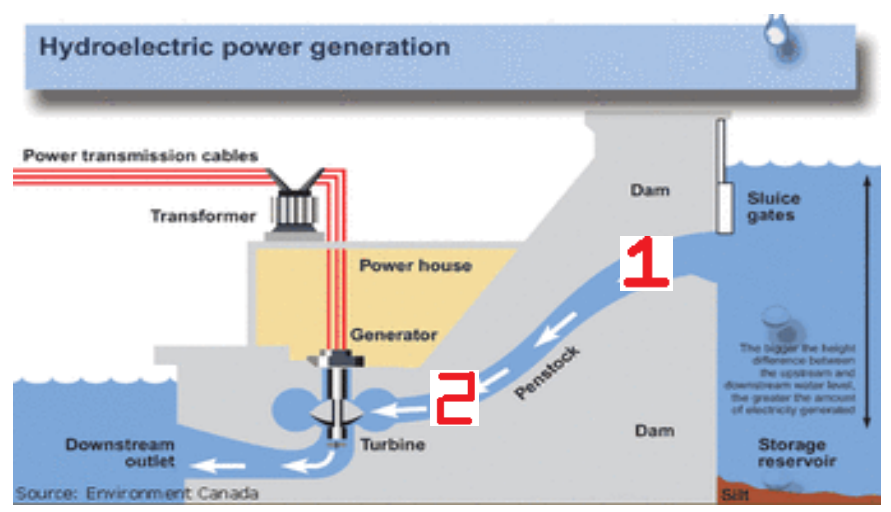

Figure (6): the shape of the pipe

- Bernoulli's equation: Which puts a relationship between pressure and velocity which is inverse relationship and states that "If the velocity of a fluid particles increases, as it travels along horizontal streamline, the pressure decreases and vice versa". As shown in figure (8). Increasing the cross-section area to increase pressure. And its equation is:

$$
P_{1}+\frac{1}{2} \rho v_{1}^{2}+\rho g h_{1}=P_{2}+\frac{1}{2} \rho v_{2}^{2}+\rho g h_{2}
$$

P: pressure $\quad \rho$ : density $\quad \mathrm{v}$ : velocity $\quad$ g: gravity $\quad \mathrm{h}$ : height

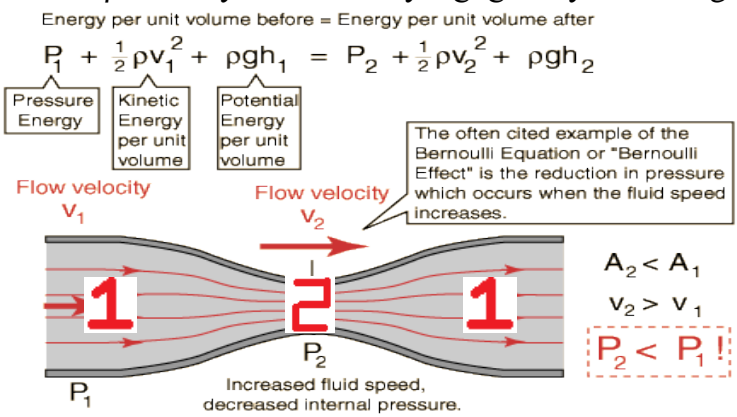

Figure (8): Bernoulli’s equation principle.

Using Bernoulli's equation to knew:

Rate of energy transfer:

$\mathrm{p}=1 / 2$ Apv3

p: power input A: area $\quad \rho$ : density $\quad \mathrm{v}$ : velocity

The relation between velocity and power is cubic relationship.

$\mathrm{P}=\mu \times \mathrm{p} \quad \mathrm{P}$ : power output $\quad \mu$ : efficiency $\quad \mathrm{p}$ : power input

- Faraday's law: He found that when a magnet is moved across a conductor, it causes electricity to flow. In large generators, electromagnets are made by circulating direct current through loops of wire wound around piles of magnetic steel foil. They are called field columns and are installed on the circumference of the rotor. The rotor is connected to the turbine shaft, and it rotates at a constant speed. When the rotor turns, it causes the field electrodes (electromagnets) to move past the conductors installed in the stator. This, in turn, leads to electricity flow and voltage development at the generator output terminals.

- Campsites: Composite materials are used in helicopter rotating blades, bullet-proof clothing for law enforcement officers, and a special tank shield. Buildings, cars, boats, trains and airplanes benefit from different types of vehicles. It is a solid consisting of two or more substances. Some compounds are manufactured by means of a process in which the fibers are embedded in another material. Usually, this will result in a stronger material and provide better qualities than both materials. Compounds not only help make stronger and lighter materials but also help extend the life of the materials. The main disadvantage of vehicles is the initial cost of researching and using special raw materials in the manufacture of the compound. However, total vehicles are the materials of the future and their manufacture can be a great professional choice.

- Exponential function: $\mathrm{f}(\mathrm{x})=\mathrm{b}^{\mathrm{x}}$ and the restrictions that $\mathrm{b}>$ 0 and that $b \neq 1$, the domain of an exponential function is the set of all real numbers. The range is the set of all positive real numbers. In this research exponential function has been used to represent the Relationship between water 
flow velocity and hydraulic gradient for different values of void ratio in peat, as shown in graph (1).

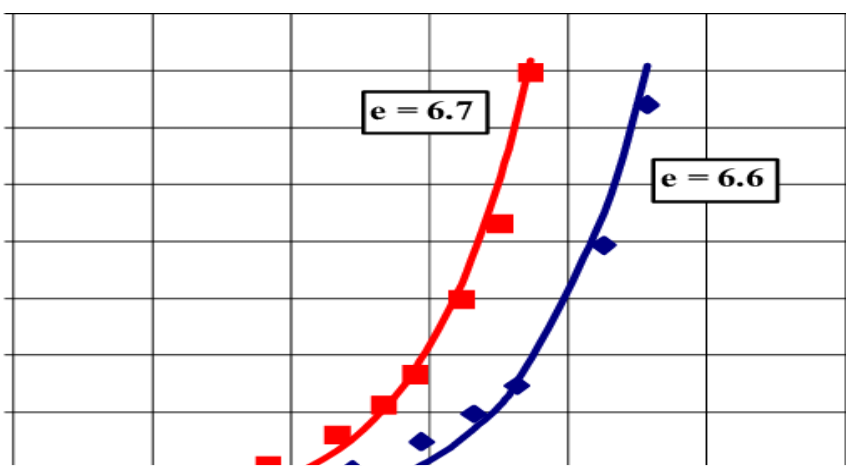

Graph (1): relationship between water flow velocity and hydraulic gradient $\cdots$

\section{CONCLUSION}

After doing a lot of researches about alternative energy, especially hydro power working on studying the factors that effect on the efficiency of water turbines. Because of fossil fuels are depleted day by day, all countries are looking for another renewable sources of energy. In this research the scoop was hydroelectricity and the purpose is studying the factors that effect on the efficiency of water turbines and make this type of energy applicable in all countries, using the relation between cross-section area, velocity and pressure.

Depending on analysis and prior researches, many researches agreed with my scoop and purpose. The scientific researcher (Yamba et, 2011) make a research paper about the relationship of hydropower with climate variability was searched with the aim of monitoring the extent of impact and in order to predict future forecasts of hydropower potential. And he found that the study also revealed that climate, projected dry years, floods and increased water demand. The results indicate that the potential of hydropower is tilted towards a gradual limit. But by doing this research, I think that climate change effect on hydroelectricity, but it still a good solution. The problem of shortage of water and water demand has been solved in this research by using seas water and oceans water using STEM subjects, especially social studies.

Another research paper made by (United States Patent No. US4843249A, 1988), in this paper V-shaped of water turbines have been choose. examine the user's conditions. In summation, the system has successfully achieved its original purpose in approaching simplicity and higher productivity.

\section{ACKNOWLEDGMENT}

This project consumed a lot of effort, attempts, and research. Implementation would not have been possible if we did not have the support of many individuals and organizations. Therefore, we would like to extend our gratitude to all of them. After Allah, we are thankful to Mrs. Mona Shaalan (Physics teacher) and Mr. Osama Abdelkarim (English Teacher).

\section{RECOMMENDATION}

After doing my research, there is many points that I want to be modified in the future researches these points are:
- Focusing on faraday's law and work on studying the factors that effect on the efficiency by using this law.

- Building the blades of the turbines from composites especially, composites that are made by a process in which fibres are embedded within another material to rotate faster.

- Studying sea water, as the idea of dams, and storage it in a big tank to solve the problem of water demand and low dissolved oxygen levels in the water.

- Studying more about the shape of the dams (turbines as Vshape).

- $\quad$ Supplying hydro power's projects in Egypt.

\section{REFERENCES}

[1] Administration, U. E. (2018, May 24). Egypt 2017 primary energy data in quadrillion Btu. Retrieved from U.S. Energy Information Administration: Retrieved October 1, 2020, from: https://www.eia.gov/international/analysis/country/EGY.

[2] Academy, K. (2015). continuity equation. Retrieved October 7, 2020, from: Khan Academy: https://www.khanacademy.org/science/physics/fluids/fluid -dynamics/a/what-is-volume-flow-rate.

[3] Academy, K. (2015). What is Bernoulli's equation? Retrieved October 8, 2020, from: Khan Academy: https://www.khanacademy.org/science/physics/fluids/fluid -dynamics/a/what-is-bernoullis-equation.

[4] Academy, K. (2016). What is Faraday's law? Retrieved October 11, 2020, from: Khan Academy: https://www.khanacademy.org/science/physics/magneticforces-and-magnetic-fields/magnetic-flux-faradayslaw/a/what-is-faradays-law.

[5] Atabani, A. E., Silitonga, A. S., Badruddin, I. A., Mahlia, T. M. I., Masjuki, H. H., \& Mekhilef, S. (2012). A comprehensive review on biodiesel as an alternative energy resource and its characteristics. Renewable and sustainable energy reviews, 16(4), 2070-2093. Retrieved November 27, 2020.

[6] Bussiere, J. L. (1989). U.S. Patent No. 4,843,249. Washington, DC: U.S. Patent and Trademark Office. Retrieved November 7, 2020.

[7] Coalition, R. R. (2016, November 15). Different Sources of Alternative Energy. Retrieved November 2, 2020, from: Renewable Resources Coalition: https://www.renewableresourcescoalition.org/alternativeenergy-sources/.

[8] Energy, U. D. (2005). Advantages and Disadvantages of Hydropower. United states: Wind and Hydropower Technologies Program. Retrieved October 7, 2020.

[9] Fearnside, P. M. (1997). Greenhouse-gas emissions from Amazonian hydroelectric reservoirs: The example of Brazil's Tucuruí Dam as compared to fossil fuel alternatives. Environmental conservation, 24(1), 64-75. Retrieved November 11, 2020.

[10] Mao, G., Liu, X., Du, H., Zuo, J., \& Wang, L. (2015). Way forward for alternative energy research: A bibliometric analysis during 1994-2013. Renewable and Sustainable 
Energy Reviews, 48, 276-286. Retrieved November 2, 2020.

[11] Taylor, K. (n.d.). Aternative Energy. Retrieved from student energy: https://www.studentenergy.org/topics/alternative-energy. Retrieved November 14, 2020.

[12] world, s. f. (n.d.). Hydroelectric Power: How it Works. Retrieved from USGS: https://www.usgs.gov/specialtopic/water-science-school/science/hydroelectric-power- how-it-works?qt-science_center_objects $=0 \# q t-$ science_center_objects. Retrieved October 1, 2020.

[13] Yamba, F. D., Walimwipi, H., Jain, S., Zhou, P., Cuamba, B., \& Mzezewa, C. (2011). Climate change/variability implications on hydroelectricity generation in the Zambezi River Basin. Mitigation and Adaptation Strategies for Global Change, 16(6), 617-628. Retrieved November 11, 2020. 